\title{
Globe
}

Revue internationale d'études québécoises

\section{Yves Bélanger : Québec inc. L'entreprise québécoise à la croisée des chemins, Montréal, Hurtubise HMH, 1998, 201 p.}

\section{Peter Graefe}

Volume 1, numéro 2, 1998

URI : https://id.erudit.org/iderudit/1000515ar

DOI : https://doi.org/10.7202/1000515ar

Aller au sommaire du numéro

Éditeur(s)

Globe, Revue internationale d'études québécoises

\section{ISSN}

1481-5869 (imprimé)

1923-8231 (numérique)

Découvrir la revue

Citer ce compte rendu

Graefe, P. (1998). Compte rendu de [Yves Bélanger : Québec inc. L'entreprise québécoise à la croisée des chemins, Montréal, Hurtubise HMH, 1998, 201 p.]

Globe, 1(2), 89-91. https://doi.org/10.7202/1000515ar d'utilisation que vous pouvez consulter en ligne.

https://apropos.erudit.org/fr/usagers/politique-dutilisation/ 
de la marche vers le statut de pays pour le Québec, alors que la réélection du Parti québécois permettrait la tenue d'un autre référendum sur la souveraineté. L'auteur insiste sur la nécessité d'une refonte du projet souverainiste afin d'y intégrer rapidement une conception civique et non ethnique.

Les arguments principaux de Claude Bariteau tiennent en deux parties : la nécessité d'informer les Québécois sur les effets de l'Indirect Rule, et celle de promouvoir une identité civique québécoise. En ce sens, ce livre est d'une actualité brûlante si l'on tient compte de l'engagement récent du chef souverainiste Lucien Bouchard. Ce dernier ne tiendra un nouveau référendum que s'il est gagnant; en ce sens, les conseils de Claude Bariteau peuvent être utiles. Bien que cet ouvrage comporte des réflexions bien personnelles, Bariteau l'a très bien documenté avec de multiples références. Il s'agit donc d'un travail solidement construit, et fort pertinent pour aborder - voire pour renouveler - l'étude du mouvement souverainiste.

Alexandre Paillé

Université du Québec à Montréal

\section{Yves Bélanger}

Québec inc.

L'entreprise québécoise à la croisée des chemins

Montréal, Hurtubise HMH, 1998, 201 p.

Avec Québec inc., Yves Bélanger met ses travaux sur la reconversion militaire de côté pour revenir au sujet de ses recherches doctorales et de son livre le mieux connu, L'Entreprise québécoise. Développement historique et dynamique contemporaine (1987). Plus qu'une simple mise à jour de ce demier, Québec inc. suit l'évolution de l'économie québécoise, surtout depuis les 
années 50, dans le contexte des débats actuels portant sur les retombées des politiques publiques et le statut du français dans les centres de pouvoirs sociaux.

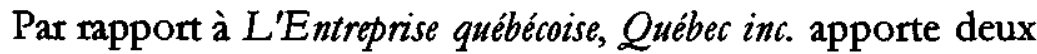
éléments nouveaux. Premièrement, Bélanger s'intéresse moins aux réseaux liant les conseils de direction et aux études de cas détaillées des sociétés québécoises. En revanche, il développe beaucoup plus l'aspect des politiques gouvernementales et leur rôle central dans la création du complexe "Québec inc.», ce qui constitue une addition heureuse. Il insiste sur un rapport de complémentarité entre les entrepreneurs et l'action étatique. La montée de "Québec inc." ne serait pas simplement le résultat d'une tentation dirigiste, comme certains le prétendent, mais plutôt la conséquence du mouvement de concentration des années 50 et 60 qui a suscité l'intervention de l'État. Cette complémentarité, que Bélanger trace au fil des années, le laisse perplexe par rapport aux multiples appels actuels au désengagement de l'État. Deuxièmement, l'évaluation des résultats de ce modèle de développement est faite d'une manière beaucoup plus systématique. Bélanger note à la fois les gains importants par rapport à l'utilisation du français dans le monde économique et la croissance d'un contrôle local sur l'économie, ainsi que l'incapacité du modèle à répondre à la pauvreté répandue et au chômage chronique.

Cependant, l'analyse pourrait être approfondie à trois égards. Premièrement, Bélanger insiste trop sur la division linguistique des entreprises, sans se demander si les comportements de ces groupes linguistiques changent avec le temps et avec la taille de l'entreprise. Il reste à démontrer si une PME anglo-québécoise contemporaine est plus sensible au contrôle local qu'une entreprise comme Bombardier axée sur les marchés étrangers, et dont une grande partie de la main-d'œuvre travaille en dehors du Québec. Deuxièmement, l'évolution de l'interaction de l'État et de l'entreprise ne prend pas assez en compte l'économie 
politique internationale, qui transforme l'interaction entre l'État et le capital dans tous les pays industrialisés. Malheureusement, Bélanger n'explique pas vraiment les différences et les similitudes entre le Québec et les autres sociétés. Troisièmement, la critique du modèle serait plus complète si Bélanger avait abordé les relations sociales, au lieu de parler seulement des devoirs des entreprises par rapport à une "population» passive. Quels groupes ou classes de la société québécoise en tirent profit, et lesquels sortent perdants? L'analyse de Bélanger est trop timide à cet égard.

Malgré ses limites, Québec inc. est un livre fort pertinent. Il est écrit dans un français clair qui vise un large lectorat, sans pourtant gêner les spécialistes. Pour ceux qui ont lu L'Entreprise québécoise, Québec inc. sera un peu redondant. Pour les autres, ce livre offre une analyse pertinente de l'économie québécoise.

Peter Graefe

Université McGill

\section{Site internet de \\ L'Office national du film du Canada http://www.onf.ca}

"Cinquante-neuf ans d'existence, cinquante-neuf ans d'histoire, cinquante-neuf ans de production cinématographique et audiovisuelle»... Dans la vague des nouvelles technologies, l'Office national du film s'est doté d'un outil de recherche en créant son site Web. Ce dernier s'adresse d'abord aux amateurs du septième art, mais les chercheurs en études québécoises seront heureux d'avoir accès à plus de 9000 documents audiovisuels, dont plusieurs portent sur des artistes et des personnages publics québécois. 